Sharif University of Technology
Scientia Iranica
Transactions E: Industrial Engineering
hCIttp://scientiairanica.sharif.edu
IRAN ICA

\title{
An integrated lot-sizing model with supplier and carrier selection and quantity discounts considering multiple products
}

\author{
S.J. Abrishami ${ }^{a}$, H. Vahdani ${ }^{a, *}$, and B. Rezaee ${ }^{b}$ \\ a. Department of Industrial Engineering, Faculty of Engineering, University of Bojnord, Bojnord, P.O. Box 94531-55111, Iran. \\ b. Department of Industrial Engineering, Faculty of Engineering, Ferdowsi University of Mashhad, Mashhad, P.O. Box 91775-1111, \\ Iran.
}

Received 9 September 2018; received in revised form 9 November 2018; accepted 6 April 2019

\section{KEYWORDS \\ Supplier selection; Inventory management; Quantity discounts; Carrier selection; Genetic algorithm.}

\begin{abstract}
Because of growing competition in the global markets and the vital role of suppliers in business success, the subject of supplier selection has attracted many researchers and practitioners during the recent years. In this study, in addition to supplier selection, the order quantity discount provided by the suppliers is considered through a new Mixed-Integer Linear Programming (MILP) model involving a manufacturer with multiple products and multiple purchasing items over multiple periods. In the proposed model, the manufacturer purchases different amounts of raw materials from selected suppliers in order to produce different products. Demands of customers are fulfilled by minimizing the total purchase, inventory, production, and transportation costs over a multi-period planning horizon. Since the problem was NP-hard, an efficient Genetic Algorithm (GA) was used to solve the large-scale real-world instances. The results were compared with the results from the exact approach wherever possible in order to investigate the efficiency of the algorithm.
\end{abstract}

(C) 2020 Sharif University of Technology. All rights reserved.

\section{Introduction}

Selecting the best supplier among a large number of suppliers sits on the top in the agendas of virtually all companies. In practice, in the increasingly competitive market, indicators such as the offered prices and quality significantly affect the selection of suppliers. The costs of the raw materials supplied and purchased comprise more than $50 \%$ of the whole cost [1].

\footnotetext{
*. Corresponding author. Tel.: +98 912 276 8426;

Fax: $+98 \quad 5832410700$

E-mail addresses: salman_abrishami@yahoo.com (S.J.

Abrishami); hvahdani@ub.ac.ir (H. Vahdani);

brezaee@um.ac.ir (B.Rezaee)
}

Indeed, there is a strong correlation between the supplier selection problem and other subjects such as inventory management as well as transportation strategies. Regarding the inventory management issues, the decision-making process becomes more complicated when suppliers offer discount conditions in order to obtain a larger market share, which in turn leads customers to have the benefit of purchasing materials at reduced costs. The subject of quantity discounts has attracted significant attention in the literature over several decades. In the field of supplier selection and order allocation within the supply chain context, some researchers have accounted for the benefits of quantity discounts in their presented models [2-9].

While paying special attention to the logistics and transportation costs by selecting the shipping system 
properly plays a vital role in the mentioned area of study, considering carrier selection is rare in the literature [10-12].

In this study, we examine a supply chain seeking to select appropriate suppliers in order to reduce the costs associated with inventory management, production management, and transportation in a dynamic planning environment. The multi-product MixedInteger Linear Programming (MILP) model, which is developed in this paper, considers the decision variables related to the selection of suppliers, the amount of raw material purchased from each supplier per period, carrier selection, and inventory management policy for each period. Accordingly, the presented model minimizes the total cost of supply chain, which includes raw materials, contracts, purchases from the supplier(s), production, storage, and carrier selection costs. To the best of our knowledge, considering all these factors simultaneously has not received any attention in the literature. Specifically, we believe our main contribution is including the procurement of raw materials for the present and upcoming production periods based on the discount patterns and converting them to final products. We deal with a variety of raw materials and products with different production plans in an integrated supplier selection model and take carrier selection into account as well.

Since modeling of the lot-sizing problems with the above-mentioned assumptions belongs to the NPhard family of problems [13,14], an efficient Genetic Algorithm (GA) is provided. In order to validate the proposed algorithm, it is implemented and analyzed for two data sets incorporating 20 samples, one consisting of small-scale sample problems with obtainable optimal solutions and the other comprising large-scale ones to which the optimal solutions cannot be reached through the exact method. A direct comparison is made based on the value of objective function and elapsed runtime.

The remainder of this paper is organized as follows. Section 2 presents a brief review of the existing relevant quantitative approaches to supplier selection and order allocation problems along with the solution methods. Section 3 presents the mathematical model and evaluates it for the small-scale examples based on several scenarios. In Section 4, the proposed GA is presented and applied to 20 small/large-scale samples and the results are compared with the exact approach. Finally, conclusions and suggestions for the future research are presented in Section 5.

\section{Literature review}

The supply of inexpensive materials from high-quality sources has great impact on developing successful business strategies. For extensive literature review of "supplier selection and decision making," one can refer to De Boer et al. [15], Ho et al. [16], and Chai et al. [17]. These studies adopt different decision-making techniques such as multi-criteria decision making, mathematical programming, and artificial intelligence along with integrated approaches (e.g., AHP, ANP, DEA, etc.).

Ghodsypour and O'Brien [18] proposed a MixedInteger Non-Linear Programming (MINLP) model with multiple sources considering the net inventory holding price as well as the transportation and ordering costs. Basnet and Leung [19] proposed a supplier selection and an inventory lot-sizing model including multiple products in a multi-period horizon to minimize the purchasing, ordering, and inventory holding costs. Liao and Rittscher [10] investigated a nonlinear multiobjective model that included minimizing the logistics and transportation costs and defective items, delivery time objectives, and the selected carrier. Rezaei and Davoodi [13] presented two Multi-Objective MixedInteger Non-Linear Programming (MOMINLP) models for multi-period lot-sizing supplier selection problems consisting of multiple products with shortage and nonshortage assumptions. Their objectives were to optimize the cost (purchasing, ordering, holding, and transportation), quality, and service level. In another study, they proposed an MINLP model with three objectives of total profit, inconsistency, and deficiency [20]. They used NSGA-II to solve their model. Mendoza and Ventura [21] proposed two MINLP models to select the best set of suppliers and to determine the proper allocation of order quantities. Their aim was to minimize the annual ordering, inventory holding, and purchasing costs under capacity and quality constraints on suppliers. Senyigit [22] presented an MILP lotsizing supplier selection model. His model incorporated a multi-product, multi-echelon defective supply chain network seeking to minimize the total relevant costs. Aliabadi et al. [23] provided an integrated non-linear binary model with multiple items for the supplier selection problem. In their study, inventory costs for both suppliers and buyers, production costs for suppliers, and transportation costs were considered. Ventura et al. [24] provided a multi-period inventory lot-sizing model for a single product in a serial supply chain. The objective of their MINLP model was to minimize the total variable costs including purchasing, production, inventory, and transportation. They also considered the all-unit quantity discounts approach for the actual transportation costs.

A stochastic lot-sizing problem with multiple suppliers along with quantity discounts was presented by Kang and Lee [25]. Their multi-objective programming model consisted of cost minimization and service level maximization functions. They used an efficient heuristic dynamic programming model to solve the MILP model. An MINLP model was presented for order 
allocation by Meena and Sarmah [8], which considered quantity discounts for potential suppliers solved by a GA approach. In their research, the suppliers were at risk of failure due to man-made or natural disruptions. Gorji et al. [26] presented a two-level supply chain with one retailer and several suppliers involving multiple periods to determine both supplier selection and inventory allocation policies. Total profit was the objective function of their MINLP model, which was solved by GA. Lee et al. [14] provided an MIP model for the lot-sizing supplier selection problem encompassing multiple periods along with all-unit and incremental discounts. They sought to minimize the costs including ordering, holding, purchasing, and transportation via an efficient GA. Choudhary and Shankar [11] represented a single-objective MIP model that considered supplier selection along with carrier selection. They allowed shortage in a single product and used the exact method to solve the model. In their latest research, Choudhary and Shankar [12] presented a goal programming model for inventory lot-sizing with the supplier selection and carrier selection decision process. Their single-product Multi-Objective Integer Linear Programming (MOILP) approach incorporated the all-unit quantity discounts, which were offered by potential suppliers. Cardenas-Barron et al. [27] presented a new reduce-and-optimize approach to solve the MILP for multi-product multi-period inventory lot sizing with the supplier selection problem solved by a heuristic algorithm. Zaheri et al. [28] proposed two models to formulate supplier selection in a single-buyer, multi-supplier, two-echelon supply chain network under all-unit quantity discount policy in which both the buyer and the vendor played the leadership role in a bi-level programming structure. Ghaniabadi and Mazinani [29] presented the single-product dynamic lotsizing problem with supplier selection and backlogging in the presence of incremental and all-unit quantity discounts. Alfaresa and Turnadi [30] provided an MIP model for a realistic multi-item lot-sizing problem with multiple suppliers, multiple time periods, quantity discounts, and backordering of shortages. In order to tackle problems with larger sizes, two heuristic solution methods were proposed including a silver-meal heuristic and a problem-specific GA. Suriyan and Rungreunganun [31] presented mathematical developments minimizing the total costs of inventory management MILP and supplier selection for inventory lot-sizing problem. They incorporated quantity discounts with multiple products in multiple periods considering supplier lead-times under the conditions of purchasing budgets. Kanchanaruangrong and Woarawichai [32] proposed a multi-product, multi-period inventory lotsizing problem with supplier selection under vehicle capacity and both all-unit and incremental quantity discounts. The objective of the buyer in their MILP model was to minimize costs including purchase cost of the products, ordering cost for the suppliers, transportation cost for the suppliers, and holding cost of the remaining inventory in each period. Zaheri et al. [33] aimed to formulate a supply chain with a buyer and multiple suppliers through bi-level programming approach with a hierarchical structure and PSO. They developed differential evolution algorithms to solve the non-linear bi-level programming problem.

Table 1 illustrates a comparison between the present research and other existing studies in this area.

In the area of supplier selection, there are a few studies that have simultaneously considered quantity discounts while shipping through selected carriers. Most of these studies focus on the single product mode and do not account for the production constraints. As a result, raw materials and time constraints, which are the most important components in a production process, have not been examined in the literature properly. The purpose of this study is to support decision makers by providing an MILP model looking to establish a trade-off among inventory holding, production, transportation, and procurement process costs within an all-unit quantity discounts environment.

\section{Problem definition and model development}

With the expansion of the competitive atmosphere, it is remarkable that in the real world, each manufacturer can satisfy their demands through different suppliers providing different quantity discounts and then, carry them using various carriers. Accordingly, we consider a supply chain containing several suppliers, which supply different raw materials, and a manufacturer that produces different types of products to fulfill the demands of customers. Raw materials are transported to the manufacturer by different transportation carriers. The total cost is the sum of the purchasing, ordering, production, inventory holding, and transportation costs. The solution to the problem determines which raw materials should be ordered, in what quantities, from which supplier(s), by which transportation carrier(s), and during which time periods. Hence, the demands of customers are all satisfied and product shortage is not allowed. There is also the possibility for the manufacturer to take advantage of discounts in purchasing raw materials at large volumes and storing them to fulfill the demands of customers in the future. Due to the production costs and time constraints in each period, the manufacturer should adopt an efficient policy on purchase quantities in order to reach a cost balance. In the meantime, the costs of shipment between the manufacturer and customers are undertaken by customers; thus, it is not considered in the model. Figure 1 shows the assumed supply chain network. 
Table 1. Summary of literature review of inventory lot sizing with supplier selection.

\begin{tabular}{|c|c|c|c|c|c|c|c|c|}
\hline Study & Formulation & Objective & Constraints & $\begin{array}{r}\text { Quantity } \\
\text { discounts }\end{array}$ & $\begin{array}{c}\text { Trans. }^{a} \\
\cos t\end{array}$ & $\begin{array}{c}\text { Carrier } \\
\text { selection }\end{array}$ & $\begin{array}{c}\text { Multi- } \\
\text { product }\end{array}$ & Remarks \\
\hline $\begin{array}{l}\text { Mendoza \& } \\
\text { Ventura [21] }\end{array}$ & MINLP & $\begin{array}{c}\text { Two models for minimizing } \\
\text { annual ordering, inventory } \\
\text { holding, and purchasing } \\
\text { costs }\end{array}$ & $\begin{array}{l}\text { Capacity of suppliers } \\
\text { and quality constraints }\end{array}$ & $\times$ & $\times$ & $x$ & $x$ & $\begin{array}{c}\text { Determining appropriate } \\
\text { level of inventory, } \\
\text { number of allocated orders, } \\
\text { and size and frequency } \\
\text { of orders }\end{array}$ \\
\hline $\begin{array}{c}\text { Rezaei \& } \\
\text { Davoodi }[20]\end{array}$ & MOMINLP & $\begin{array}{c}\text { Three ob jectives of total } \\
\text { profit, inconsistency, } \\
\text { and deficiency }\end{array}$ & $\begin{array}{l}\text { Capacity of suppliers, } \\
\text { budget and storage } \\
\text { capacity constraints }\end{array}$ & $x$ & $\checkmark$ & $x$ & $\checkmark$ & $\begin{array}{c}\text { Employing GA (NSGA-II) } \\
\text { to solve the model and } \\
\text { produce Pareto-optimal } \\
\text { solutions }\end{array}$ \\
\hline Senyigit [22] & MILP & $\begin{array}{l}\text { Minimizing total cost of } \\
\text { purchasing-production and } \\
\text { distribution strategy }\end{array}$ & $\begin{array}{l}\text { Capacity of suppliers, } \\
\text { production and storage } \\
\text { capacity constraints }\end{array}$ & $x$ & $\checkmark$ & $x$ & $\checkmark$ & $\begin{array}{l}\text { Considering defect rates, } \\
\text { a case study problem }\end{array}$ \\
\hline $\begin{array}{l}\text { Aliabadi } \\
\text { et al. [23] }\end{array}$ & MINLP & $\begin{array}{l}\text { Maximum annual income } \\
\text { (total cost is the } \\
\text { sum of the costs to } \\
\text { suppliers and retailers) }\end{array}$ & $\begin{array}{c}\text { Capacity of suppliers } \\
\text { and storage capacity } \\
\text { constraints, inventory shortage } \\
\text { and unacceptable surplus }\end{array}$ & $x$ & $\checkmark$ & $x$ & $x$ & A new two-level GA \\
\hline $\begin{array}{l}\text { Ventura } \\
\text { et al. [24] }\end{array}$ & MINLP & $\begin{array}{l}\text { Minimizing total variable } \\
\text { cost including purchasing, } \\
\text { production, inventory, } \\
\text { and transportation }\end{array}$ & $\begin{array}{l}\text { Capacity of suppliers, } \\
\text { production and distribution } \\
\text { capacities, and inventory } \\
\text { capacity constraints }\end{array}$ & $\checkmark$ & $\checkmark$ & $x$ & $x$ & $\begin{array}{l}\text { All-unit discount for } \\
\text { transportation costs } \\
\text { structure }\end{array}$ \\
\hline Gorji et al. [26] & MINLP & $\begin{array}{l}\text { Maximizing total profit } \\
\text { (purchasing, ordering, } \\
\text { inspection, holding, } \\
\text { penalty, and } \\
\text { transportation) }\end{array}$ & $\begin{array}{l}\text { Capacity of suppliers and } \\
\text { total capital constraints, } \\
\text { inventory balance equations }\end{array}$ & $x$ & $\checkmark$ & $x$ & $\checkmark$ & $\begin{array}{l}\text { Presenting GA to } \\
\text { solve the model }\end{array}$ \\
\hline $\begin{array}{l}\text { Kang \& } \\
\text { Lee }[25]\end{array}$ & MOILP & $\begin{array}{l}\text { Minimizing total ordering, } \\
\text { holding, purchase, and } \\
\text { shortage costs; maximizing } \\
\text { system service level }\end{array}$ & $\begin{array}{l}\text { Inventory balance equations } \\
\text { and shortage constraints }\end{array}$ & $\checkmark$ & $x$ & $x$ & $x$ & $\begin{array}{l}\text { Constructing an efficient } \\
\text { Heuristic Dynamic } \\
\text { Programming (HDP) for } \\
\text { solving large-scale } \\
\text { stochastic lot-sizing } \\
\text { problems }\end{array}$ \\
\hline Lee et al. [14] & MIP & $\begin{array}{l}\text { Minimizing total ordering, } \\
\text { holding, purchasing, and } \\
\text { transportation cost }\end{array}$ & $\begin{array}{c}\text { Inventory balance } \\
\text { equations }\end{array}$ & $\checkmark$ & $\checkmark$ & $x$ & $x$ & $\begin{array}{l}\text { Proposing an efficient } \\
\text { GA to solve the model }\end{array}$ \\
\hline $\begin{array}{l}\text { Choudhary \& } \\
\text { Shankar [11] }\end{array}$ & MIP & $\begin{array}{l}\text { Minimizing total cost to } \\
\text { the buyer including } \\
\text { purchasing, transaction, } \\
\text { and inventory cost }\end{array}$ & $\begin{array}{l}\text { Inventory balance equations, } \\
\text { ordering cost, storage } \\
\text { and capacity of suppliers } \\
\text { constraints, s2ervice } \\
\text { level requirement }\end{array}$ & $\sqrt{ }$ & $\checkmark$ & $\checkmark$ & $x$ & $\begin{array}{c}\text { A MIP model which } \\
\text { determines the timing of } \\
\text { procurements, lot-sizes, suppliers, } \\
\text { and carriers }\end{array}$ \\
\hline $\begin{array}{l}\text { Choudhary \& } \\
\text { Shankar [12] }\end{array}$ & MOILP & $\begin{array}{l}\text { Minimizing net rejected } \\
\text { items, net costs, } \\
\text { and net late } \\
\text { delivered items }\end{array}$ & $\begin{array}{c}\text { Inventory balance equations, } \\
\text { ordering cost, storage } \\
\text { and capacity of suppliers } \\
\text { constraints, service } \\
\text { level requirement }\end{array}$ & $\checkmark$ & $\checkmark$ & $\checkmark$ & $x$ & $\begin{array}{l}\text { Three variants of goal } \\
\text { programming used to } \\
\text { solve the problem }\end{array}$ \\
\hline Zaheri et al. [28] & $\begin{array}{l}\text { Mixed } \\
\text { binary } \\
\text { NLBLP }\end{array}$ & $\begin{array}{l}\text { First model: total } \\
\text { annual cost of } \\
\text { purchasing, order, and } \\
\text { holding for the leader; } \\
\text { Second model: total } \\
\text { annual cost of production, } \\
\text { setup, and holding for } \\
\text { the suppliers }\end{array}$ & $\begin{array}{l}\text { Production capacity, } \\
\text { supplier capacity }\end{array}$ & $\sqrt{ }$ & $x$ & $\times$ & $x$ & $\begin{array}{l}\text { Using PSO algorithm } \\
\text { to solve their model }\end{array}$ \\
\hline $\begin{array}{l}\text { Ghaniabadi \& } \\
\text { Mazinani [29] }\end{array}$ & MILP & $\begin{array}{l}\text { Two models for minimizing } \\
\text { the total costs of ordering, } \\
\text { unit purchase, holding, } \\
\text { and backlogging }\end{array}$ & $\begin{array}{c}\text { Inventory balance } \\
\text { equations }\end{array}$ & $\sqrt{ }$ & $x$ & $x$ & $x$ & $\begin{array}{l}\text { Using commercial } \\
\text { optimization software to solve } \\
\text { the model }\end{array}$ \\
\hline $\begin{array}{c}\text { Alfaresa \& } \\
\text { Turnadi [30] }\end{array}$ & MIP & $\begin{array}{l}\text { Minimizing the sum of } \\
\text { the ordering, purchasing, } \\
\text { transportation, inventory } \\
\text { holding, and shortage costs }\end{array}$ & $\begin{array}{c}\text { Inventory balance constraint, } \\
\text { transportation capacity } \\
\text { constraints, budget limits, } \\
\text { capacity constraints } \\
\text { on storage volume }\end{array}$ & $\checkmark$ & $\checkmark$ & $\times$ & $\times$ & $\begin{array}{l}\text { Using two heuristic } \\
\text { solution methods: the } \\
\text { silver-meal heuristic } \\
\text { and GA }\end{array}$ \\
\hline
\end{tabular}

${ }^{\mathrm{a}}$ Trans.: Transportation. 
Table 1. Summary of literature review of inventory lot sizing with supplier selection (continued).

\begin{tabular}{|c|c|c|c|c|c|c|c|c|}
\hline Study & Formulation & Objective & Constraints & $\begin{array}{l}\text { Quantity } \\
\text { discounts }\end{array}$ & $\begin{array}{c}\text { Trans. }^{a} \\
\text { cost }\end{array}$ & $\begin{array}{c}\text { Carrier } \\
\text { selection }\end{array}$ & $\begin{array}{c}\text { Multi- } \\
\text { product }\end{array}$ & Remarks \\
\hline $\begin{array}{c}\text { Cardenas-Barron } \\
\text { et al. }[27]\end{array}$ & MILP & $\begin{array}{l}\text { Minimizing the total purchase } \\
\text { cost of the products, } \\
\text { the total ordering cost, } \\
\text { and the total holding cost } \\
\text { for carrying inventory }\end{array}$ & $\begin{array}{c}\text { Avoid } \\
\text { shortages }\end{array}$ & $x$ & $x$ & $\times$ & $\checkmark$ & $\begin{array}{c}\text { Heuristic algorithm based } \\
\text { on Reduce and Optimize } \\
\text { Approach (ROA) using } \\
\text { CPLEX to solve } \\
\text { the model }\end{array}$ \\
\hline $\begin{array}{c}\text { Suriyan \& } \\
\text { Rungreunganun } \\
{[31]}\end{array}$ & MILP & $\begin{array}{l}\text { Minimizing total inventory } \\
\text { costs, which consist of product } \\
\text { costs, ordering costs, } \\
\text { inventory holding costs, } \\
\text { and transportation } \\
\text { costs }\end{array}$ & $\begin{array}{l}\text { Inventory constraints, } \\
\text { limitation of product } \\
\text { order, budget limits }\end{array}$ & $\checkmark$ & $\checkmark$ & $\times$ & $\checkmark$ & $\begin{array}{l}\text { Using LINGO to } \\
\text { solve the model }\end{array}$ \\
\hline $\begin{array}{l}\text { Kanchanaruangrong } \\
\& \text { Woarawichai }[32]\end{array}$ & MILP & $\begin{array}{l}\text { Minimizing total costs } \\
\text { including purchase cost } \\
\text { of the products, ordering cost, } \\
\text { transportation cost, } \\
\text { and holding cost }\end{array}$ & $\begin{array}{l}\text { Inventory balance } \\
\text { equations, buyer } \\
\text { storage capacity }\end{array}$ & $\checkmark$ & $\checkmark$ & $x$ & $\checkmark$ & $\begin{array}{l}\text { Using LINGO to } \\
\text { solve the model }\end{array}$ \\
\hline This paper & MILP & $\begin{array}{l}\text { Minimizing total cost to } \\
\text { the buyer, including } \\
\text { purchasing, ordering, } \\
\text { transportation, inventory, } \\
\text { and production costs }\end{array}$ & $\begin{array}{l}\text { Inventory balance equations, } \\
\text { capacity constraint of } \\
\text { suppliers, storage capacity } \\
\text { of raw materials, and } \\
\text { production constraint }\end{array}$ & $\checkmark$ & $\checkmark$ & $\checkmark$ & $\checkmark$ & $\begin{array}{l}\text { Production costs and } \\
\text { purchase of various raw } \\
\text { materials to produce } \\
\text { products in multiple } \\
\text { periods; Using GA to } \\
\text { solve the model }\end{array}$ \\
\hline
\end{tabular}

a Trans.: Transportation.

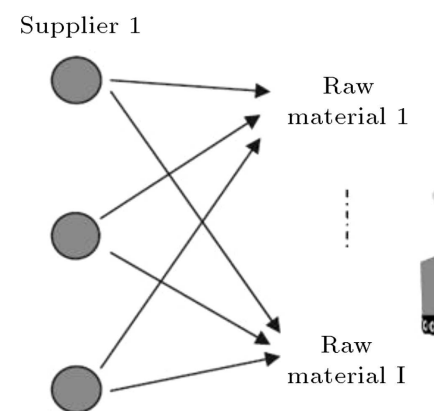

Supplier $J$

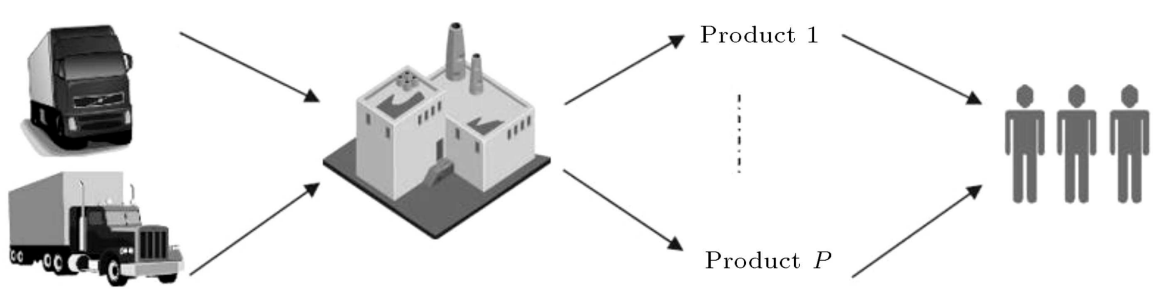

Manufacturer

Customers

Figure 1. Supply chain network. follows:

Other assumptions made in this study are as

- The demand quantities for multiple products are known but inconstant over multiple planning periods;

- The price of unit raw material received from suppliers depends on the order quantity in each period. With this in mind, all-unit quantity discount is applied;

- Inventory holding costs are known for raw material and product, and they vary in each period;

- The planning horizon is finite and known. The length of each period is fixed;

- Transportation costs depend on the selected carrier(s), which in turn depend on the selected supplier and period;

- The supply capacity of suppliers is finite and different in each period;
- The storage capacity of raw materials and products is finite and different in each period;

- Each carrier has a distinct capacity, which is limited;

- The number of available carriers is finite and different in each period.

The notations of the model are presented as follows:

\section{Set indices:}

$i \quad$ Index of the raw materials purchased from the suppliers $(i=1,2, \ldots, I)$

$j \quad$ Index of the suppliers $(j=1,2, \ldots, J)$

$k \quad$ Index of the all-unit price break levels $(k=1,2, \ldots, K)$

$t \quad$ Index of the discrete planning periods $(t=1,2, \ldots, T)$

$l \quad$ Index of the transportation carriers $(l=1,2, \ldots, L)$

$p \quad$ Index of the products $(p=1,2, \ldots, P)$ 


\section{Parameters:}

$D_{p t} \quad$ Total demand of the $p$-th product in period $t$

$O_{j t} \quad$ Cost of placing order to supplier $j$ in period $t$

$P R_{p t} \quad$ Production cost per unit of product $p$ in period $t$

$C P_{t} \quad$ Storage capacity of the products of the manufacturer in period $t$

$t_{p} \quad$ The time needed to produce one unit of product $p$

$T_{t} \quad$ Total time available for production in period $t$

$\alpha_{i p} \quad$ Units of raw material $i$ required to produce one unit of product $p$

$C R_{t} \quad$ Storage capacity for the raw materials of the manufacturer in period $t$

$C S_{i j t} \quad$ Supply capacity of raw material $i$ from supplier $j$ in period $t$

$W_{i} \quad$ Cubic volume of raw material $i$

$U V_{l} \quad$ Maximum volume capacity of carrier $l$

$U N V_{l t} \quad$ Maximum available number of carriers $l$ in period $t$

$B_{i j k t} \quad$ The quantity at which all-unit price break $k$ occurs at supplier $j$ in period $t$ for raw material $i$

$P_{i j k t} \quad$ Cost of procuring one unit of raw material $i$ from supplier $j$ at price break level $k$ in period $t$

$h_{i t} \quad$ Inventory holding cost per unit raw material $i$ during period $t$

$H_{p t} \quad$ Inventory holding cost per unit product $p$ during period $t$

$C V_{j l t} \quad$ Transportation cost from supplier $j$ by carrier $l$ in period $t$

$M \quad$ A sufficiently large number

Decision variables:

$X_{i j k t l} \quad$ Quantity of raw material $i$ purchased from supplier $j$ at price break level $k$ in period $t$ transported through carrier $l$

$Y_{p t} \quad$ Quantity of product type $p$ manufactured in period $t$

$N V_{j l t} \quad$ Quantity of carrier $l$ used in period $t$ for supplier $j$

$z_{j t} \quad$ A binary variable: 1 if supplier $j$ is chosen in period $t, 0$ otherwise

$v_{j l t} \quad$ A binary variable: 1 if carrier $l$ is used in period $t$ for supplier $j, 0$ otherwise

$I_{i t} \quad$ Inventory level of raw material $i$ at the end of period $t$

$I_{p t}^{\prime} \quad$ Inventory level of product $p$ at the end of period $t$ $b_{i j k t} \quad$ A binary variable: 1 if the lot-size of raw material $i$ purchased from supplier $j$ is placed at price break level $k$ in period $t, 0$ otherwise

\subsection{Problem formulation}

According to the above parameters, decision variables, and model assumptions, the mathematical model can be formulated as follows:

$$
\begin{aligned}
& \text { Min } Z=Z_{1}+Z_{2}+Z_{3}+Z_{4}+Z_{5}, \\
& Z_{1}=\sum_{i} \sum_{j} \sum_{k} \sum_{t} \sum_{l} X_{i j k t l} P_{i j k t}, \\
& Z_{2}=\sum_{t} \sum_{j} z_{j t} O_{j t}, \\
& Z_{3}=\sum_{t} \sum_{p} Y_{p t} P R_{p t}, \\
& Z_{4}=\sum_{t} \sum_{i} I_{i t} h_{i t}+\sum_{t} \sum_{p} I_{p t}^{\prime} H_{p t}, \\
& Z_{5}=\sum_{t} \sum_{j} \sum_{l} C V_{j l t} N V_{j l t} .
\end{aligned}
$$

Subject to:

$$
\begin{aligned}
& I_{p t}^{\prime}=I_{p(t-1)}^{\prime}+Y_{p t}-D_{p t} \quad \forall p, t>1 \\
& \sum_{p} I_{p t}^{\prime} \leq C P_{t} \quad \forall t \\
& \sum_{p} Y_{p t} t_{p} \leq T_{t} \quad \forall t \\
& I_{i t}=I_{i(t-1)}+\sum_{j} \sum_{k} \sum_{l} X_{i j k t l}-\sum_{p} Y_{p t} \alpha_{i t}
\end{aligned}
$$

$\sum_{i} I_{i t} \leq C_{R t} \quad \forall t$

$\sum_{k} \sum_{l} X_{i j k t l} \leq C S_{i j t} Z_{j t} \quad \forall i, j, t$

$\sum_{l} v_{j l t}=z_{j t} \quad \forall j, t$

$\sum_{i} \sum_{k} X_{i j k t l} \leq M v_{j l t}, \quad \forall i, j, k, t, l$,

$\sum_{k} \sum_{i} X_{i j k t l} W_{i} \leq N V_{j l t} U V_{l}+M\left(1-v_{j l t}\right)$ 


$$
\begin{aligned}
& \sum_{j} N V_{j l t} \leq U N V_{l t} \quad \forall l, t \\
& B_{i j(k-1) t} b_{i j k t} \leq \sum_{l} X_{i j k t l} \leq B_{i j k t} b_{i j k t}
\end{aligned}
$$$$
\forall i, j, t, k>1
$$$$
\sum_{k} b_{i j k t}=z_{j t} \quad \forall i, j, t
$$

$$
I_{i t} \cdot I_{p t}^{\prime} \geq 0 \quad \forall i, t, p
$$

$$
X_{i j k t l}, Y_{p t}, N V_{j l t} \geq 0
$$$$
\text { and integer } \forall i, j, k, t, l, p \text {, }
$$

$$
z_{j t}, v_{j l t}, b_{i j k t} \in\{0,1\} \quad \forall i, j, k, l, t .
$$

Objective function (1) is to minimize the total cost over the planning horizon. It consists of five terms: (1a) costs of the purchase, (1b) ordering costs, (1c) production costs, (1d) inventory holding costs for the remaining inventory at the end of each period, which includes raw materials and product holding costs, and (1e) transportation costs. Constraint (2) represents the inventory balance of products in different periods. Constraint (3) enforces storage capacity for products per period. Constraint (4) controls the capability of production in each period by time-limit production. Constraint (5) computes the amount of raw materials that remains at the end of each period. Constraint (6) determines the storage capacity for raw materials per period. Constraint (7) ensures that raw materials will be provided through contracts of suppliers with the manufacturer. The purchase quantity must not exceed the maximum supplier capacity. Constraint (8) indicates that if the contract is performed by a supplier, a transportation system must also be considered. Constraint (9) ensures that if the carrier is not assigned to a supplier, the supplier will not be able to ship the raw materials. Constraint (10) determines the number of carriers used for shipping with respect to the volume. Constraint (11) guarantees that the total number of carriers deployed for transportation will not surpass the maximum number of carriers. Constraints (12) and (13) are related to the all-unit quantity discount plan. According to these constraints, each lot is purchased from suppliers at a specified price break in the discount interval. Only one price break level, which is applied to the lot-size for each period and supplier, is considered. Finally, Constraints (14)-(16) identify the types of different variables.

\subsection{Numerical example}

To evaluate the performance of the proposed mathematical model, a numerical example is provided in which the manufacturer wants to purchase three types of raw materials to produce two types of products over a planning horizon of five periods through three potential suppliers. Demands of customers are 20 and 30 for products number 1 and 2 in each period, respectively. The coefficient of raw materials usage for production, the volume of raw materials, and the capacity of suppliers - which are considered constant through different periods - are given in Table 2. The ordering costs are assumed to be constant in each period, which are 120,100 , and 110 in a monetary unit, respectively. Inventory holding costs for each raw material unit are 2,3 , and 2 in a monetary unit, respectively. Inventory holding costs of products, the time needed to produce one unit of each product, and production costs are shown in Table 3 . The total production time available in each period is 500 time units. The storage capacities for the raw materials and products in manufacturer area are 1000 and 100 per period, respectively.

The proposed prices of the suppliers for raw materials considering the price break levels are presented in Table 4. In this example, the discount levels for

Table 2. Data on the raw materials and capacities of suppliers.

\begin{tabular}{ccccccc}
\hline & & & \multicolumn{3}{c}{$\boldsymbol{C S}_{\boldsymbol{i j \boldsymbol { t }}}$} \\
\cline { 2 - 3 } \cline { 5 - 7 } $\boldsymbol{i}$ & \multicolumn{2}{c}{$\boldsymbol{\alpha}_{\boldsymbol{i} \boldsymbol{p}}$} & & \multicolumn{3}{c}{$\boldsymbol{J}$} \\
\cline { 6 - 8 } & $\boldsymbol{P}=\mathbf{1}$ & $\boldsymbol{P}=\mathbf{2}$ & $\boldsymbol{W}_{\boldsymbol{i}}$ & $\mathbf{1}$ & $\mathbf{2}$ & $\mathbf{3}$ \\
\hline 1 & 1 & 2 & 2 & 200 & 300 & 500 \\
2 & 3 & 1 & 1 & 300 & 250 & 700 \\
3 & 2 & 2 & 3 & 250 & 500 & 600 \\
\hline
\end{tabular}

\begin{tabular}{|c|c|c|c|c|}
\hline \multirow[b]{3}{*}{$j$} & \multirow[b]{3}{*}{ Quantity level } & \multicolumn{3}{|c|}{$P_{i j k t}$} \\
\hline & & \multicolumn{3}{|c|}{$I$} \\
\hline & & 1 & 2 & 3 \\
\hline \multirow{3}{*}{1} & $0<Q<100$ & 10 & 15 & 20 \\
\hline & $100 \leq Q<300$ & 8 & 14 & 18 \\
\hline & $Q \geq 300$ & 7 & 12 & 15 \\
\hline \multirow{3}{*}{2} & $0<Q<100$ & 11 & 17 & 19 \\
\hline & $100 \leq Q<300$ & 9 & 15 & 17 \\
\hline & $Q \geq 300$ & 8 & 14 & 15 \\
\hline \multirow{3}{*}{3} & $0<Q<100$ & 10 & 16 & 18 \\
\hline & $100 \leq Q<300$ & 9 & 14 & 17 \\
\hline & $Q \geq 300$ & 8 & 13 & 16 \\
\hline
\end{tabular}

Table 3. Data on manufacturer.

\begin{tabular}{cccc}
\hline Product & $\boldsymbol{H}_{\boldsymbol{p} \boldsymbol{t}}$ & $\boldsymbol{t}_{\boldsymbol{p}}$ & $\boldsymbol{P R}_{\boldsymbol{p} \boldsymbol{t}}$ \\
\hline $\mathbf{1}$ & 5 & 10 & 10 \\
$\mathbf{2}$ & 5 & 12 & 11 \\
\hline
\end{tabular}

Table 4. Dataset of the suppliers for the numerical example. 
Table 5. Transportation data.

\begin{tabular}{|c|c|c|c|c|c|c|c|c|c|c|}
\hline & & \multicolumn{3}{|c|}{$C V_{j l t}$} & \multicolumn{5}{|c|}{$U N V_{l t}$} & \multirow[t]{3}{*}{$U V_{l}$} \\
\hline & & \multicolumn{3}{|c|}{$\boldsymbol{J}$} & \multicolumn{5}{|c|}{$T$} & \\
\hline & & 1 & 2 & 3 & 1 & 2 & 3 & 4 & 5 & \\
\hline \multirow{2}{*}{$l$} & 1 & 25 & 35 & 45 & 40 & 50 & 50 & 45 & 40 & 20 \\
\hline & 2 & 40 & 50 & 60 & 30 & 60 & 50 & 40 & 35 & 30 \\
\hline
\end{tabular}

different periods and raw materials are assumed to be identical.

Table 5 shows the transportation costs proposed by the suppliers considering the carriers and their maximum capacity volume. Moreover, it displays the maximum number of available carriers, which varies by period.

Table 6 shows the solution obtained by solving the model. As the results show, the optimal solution is to purchase the first raw material (400 units), the second one (450 units), and a fraction of the third one (200 units) from the first supplier. The second supplier is selected to supply 300 units of the third raw material because of better discount and closer distance of supplier 1 , which is obvious in Table 6 .

\subsection{Scenarios}

For a more comprehensive assessment of the problem parameters, different scenarios have been examined. In this section, we assess two important scenarios to delve into the impact of different quantity discounts and inventory costs on the objective function, while keeping the rest of the parameters at their base values. Three additional scenarios assess the effects of quantity discounts and five further scenarios investigate the inventory costs for the raw materials and products.

\subsubsection{Analysis of quantity discounts}

As mentioned before, to analyze the effects of quantity discounts, three sub-scenarios are defined and provided in Table 7. In sub-scenario 1, the first supplier does not offer any discounts, whereas suppliers 2 and 3 offer

Table 7. Impact of quantity discount.

\begin{tabular}{cccc}
\hline & \multicolumn{3}{c}{ Sub-scenarios } \\
\cline { 2 - 4 } & $X_{11111}=85$ & $X_{11111}=85$ & $X_{11111}=81$ \\
& $X_{21111}=90$ & $X_{11141}=62$ & $X_{11121}=80$ \\
& $X_{12222}=195$ & $X_{11151}=58$ & $X_{11131}=79$ \\
& $X_{12242}=120$ & $X_{21111}=90$ & $X_{11141}=82$ \\
& $X_{32212}=100$ & $X_{21141}=30$ & $X_{11151}=78$ \\
& $X_{32242}=100$ & $X_{21151}=30$ & $X_{21111}=90$ \\
& $X_{32322}=300$ & $X_{31141}=42$ & $X_{21121}=93$ \\
& $X_{23322}=300$ & $X_{31151}=58$ & $X_{21131}=87$ \\
& & $X_{31211}=100$ & $X_{21141}=90$ \\
& & $X_{13222}=195$ & $X_{21151}=90$ \\
& & $X_{23322}=300$ & $X_{31131}=98$ \\
& & $X_{33322}=300$ & $X_{31151}=98$ \\
& & & $X_{31211}=100$ \\
Total cost & 26575 & & $X_{31221}=102$ \\
\hline Supplier 1 & $\sim 18 \%$ & $\sim 41 \%$ & $100 \%$ \\
Supplier 2 & $\sim 60 \%$ & $\sim 0 \%$ & $0 \%$ \\
Supplier 3 & $\sim 22 \%$ & $\sim 59 \%$ & $0 \%$ \\
\hline
\end{tabular}

Table 6. Results for the base example.

\begin{tabular}{lc}
\hline Objective & Value \\
\hline Purchasing cost (Z1) & 17,050 \\
Ordering cost (Z2) & 460 \\
Production cost (Z3) & 2,650 \\
Inventory holding cost (Z4) & 1,070 \\
Transportation cost (Z5) & 3,825 \\
Total Objective & $\mathbf{2 5 , 0 5 5}$ \\
\hline
\end{tabular}

\begin{tabular}{cccc}
\hline $\begin{array}{c}\text { The amount of raw } \\
\text { materials purchased }\end{array}$ & $\begin{array}{c}\text { Inventory quantities } \\
\text { for raw materials } \\
\text { and products }\end{array}$ & $\begin{array}{c}\text { Quantity of } \\
\text { manufactured products }\end{array}$ & $\begin{array}{c}\text { The number of } \\
\text { used carriers }\end{array}$ \\
\hline $\mathrm{X}_{11211}=\mathbf{1 0 0}$ & $\boldsymbol{I}_{\mathbf{1 1}}=20$ & $\boldsymbol{Y}_{\mathbf{1 1}}=20$ & $\boldsymbol{N}_{\mathbf{1 1 1}}=30$ \\
$\mathrm{X}_{11221}=\mathbf{2 0 0}$ & $\boldsymbol{I}_{\mathbf{2 1}}=10$ & $\boldsymbol{Y}_{\mathbf{1 2}}=80$ & $\mathbf{N} \boldsymbol{V}_{\mathbf{1 1 2}}=35$ \\
$\mathrm{X}_{11241}=\mathbf{1 0 0}$ & $\boldsymbol{I}_{\mathbf{1 2}}^{\prime}=60$ & $\boldsymbol{Y}_{\mathbf{2 1}}=30$ & $\mathbf{N} \boldsymbol{V}_{\mathbf{1 1 4}}=28$ \\
$\mathrm{X}_{21141}=\mathbf{5 0}$ & $\boldsymbol{I}_{\mathbf{1 3}}^{\prime}=40$ & $\boldsymbol{Y}_{\mathbf{2 2}}=70$ & $\mathbf{N} \boldsymbol{V}_{\mathbf{2 2 2}}=30$ \\
$\mathrm{X}_{21211}=\mathbf{1 0 0}$ & $\boldsymbol{I}_{\mathbf{1 4}}^{\prime}=20$ & $\mathbf{Y}_{\mathbf{2 4}}=50$ & \\
$\mathrm{X}_{21321}=\mathbf{3 0 0}$ & $\boldsymbol{I}_{\mathbf{2 2}}^{\prime}=40$ & & \\
$\mathrm{X}_{31211}=\mathbf{1 0 0}$ & $\boldsymbol{I}_{\mathbf{2 3}}^{\prime}=10$ & & \\
$\mathrm{X}_{31241}=\mathbf{1 0 0}$ & $\boldsymbol{I}_{\mathbf{2 4}}^{\prime}=30$ & & \\
$\mathrm{X}_{32322}=\mathbf{3 0 0}$ & & & \\
\hline
\end{tabular}




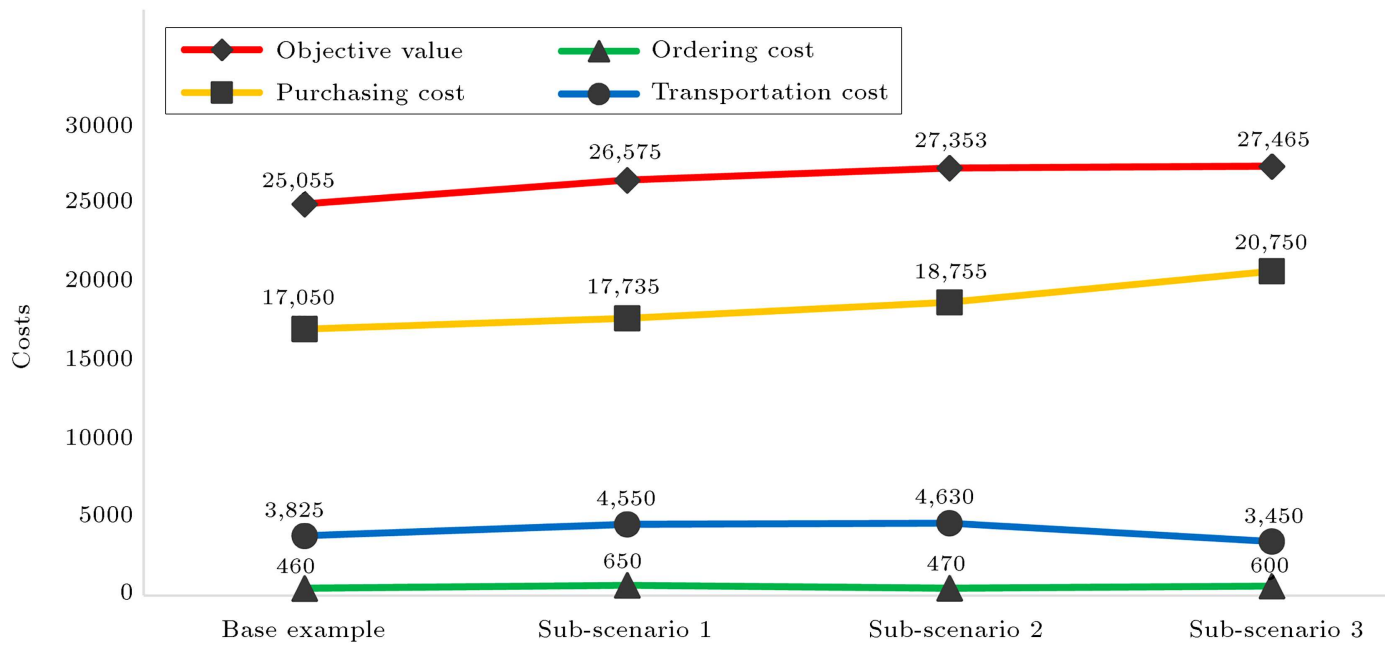

Figure 2. Effects of quantity discounts on the costs.

their previous discounts. As expected, we observe that most of the materials (over $82 \%$ of all purchases) are now sourced from suppliers 2 and 3 . Thus, purchase of the manufacturer from supplier 1 is decreased by about $60 \%$.

In the second sub-scenario, only supplier 3 offers quantity discounts and, as a result, a significant percentage of the purchases $(59 \%)$ are made from supplier 3. In addition, because of the proximity of supplier 1 , the remaining purchases are sourced from supplier 1 .

In sub-scenario 3, suppliers do not offer any discounts and the selection is made based on other criteria. Due to more appropriate conditions offered by the first supplier, all purchases are allocated to it.

Figure 2 illustrates the effects of these variations on the costs. As expected, by eliminating the quantity discount advantage, the total costs as well as the purchasing costs increase, but the costs of ordering and transportation do not show any significant difference. The model strives to find the best trade-off among these cost categories to compensate for the increase in the purchasing costs.

\subsubsection{Analysis of inventory holding costs}

Table 8 illustrates how the amount of purchases is affected by the inventory holding costs. There are five scenarios in which the effects of changes on inventory holding cost for the products and the raw materials are examined. In scenarios 1 and 2, the inventory holding cost for the products is decreased and increased, respectively.

In scenario 1 , the reduction in the holding costs of products drives the manufacturer to supply the raw materials and produce the final products less frequently and in larger sizes in order to take advantage of the offered discounts. From Table 8, this practice reduces the total ordering cost, whereas the total inventory of the products at the end of each period will significantly increase. In scenario 2, as expected, the significant increase in inventory holding costs of the products leads to zero inventory level for the products at the end of each period and an increase in the number of orders.

In scenario 3 , as the inventory holding costs of the raw materials decrease, the manufacturer supplies the raw materials in larger quantities, which in turn decreases the inventory level of the final products at the end of each time period. This policy will also provide the manufacturer with more opportunities to take advantage of the offered discount privileges. In scenario 4 , as the inventory holding costs of raw materials increase, the objective function increases, whereas the decision variables remain unchanged compared to the basic example. This is a direct effect of the trade-off between the potential discount benefits of ordering in larger quantities and the rise in holding costs, which prompts the manufacturer to follow the existing course of ordering and production policies. In scenario 5, the raw materials undergo a substantial increase in the holding costs to the extent that they cannot be offset by the suggested discount benefits. Table 8 shows the change in the order and production policies. The inventory only comprises the final products, i.e. no raw material inventory is held at the end of any time period.

In a nutshell, our analyses show that the costs related to raw materials and the final products have consequential influences on supply chain policies, performance, and costs. Therefore, we recommend that supply chain players should acquire more accurate business cost estimations.

\section{Solution method}

In the literature, because of the NP-hardness of lot sizing, different methods have been adopted to solve the supplier selection problem. The results of applying 
Table 8. Impact of inventory holding costs.

\begin{tabular}{|c|c|c|c|c|c|}
\hline & \multicolumn{2}{|c|}{$\begin{array}{l}\text { Inventory holding cost for } \\
\text { products }\left(H_{1 t}, H_{2 t}\right)\end{array}$} & \multicolumn{3}{|c|}{$\begin{array}{c}\text { Inventory holding cost for raw } \\
\text { materials }\left(h_{1 t}, h_{2 t}, h_{3 t}\right)\end{array}$} \\
\hline & $\begin{array}{c}\text { Scenario } 1 \\
(0.5,0.5)\end{array}$ & $\begin{array}{c}\text { Scenario } 2 \\
(10,10)\end{array}$ & $\begin{array}{c}\text { Scenario } 3 \\
(1,1,1)\end{array}$ & $\begin{array}{c}\text { Scenario } 4 \\
(5,5,5)\end{array}$ & $\begin{array}{c}\text { Scenario } 5 \\
(13,13,13)\end{array}$ \\
\hline & $X_{11211}=200$ & $X_{11121}=60$ & $X_{11211}=200$ & $X_{11211}=100$ & $X_{11111}=80$ \\
\hline & $X_{11233}=200$ & $X_{11151}=40$ & $X_{11231}=100$ & $X_{11221}=200$ & $X_{11221}=200$ \\
\hline & $X_{21232}=150$ & $X_{11211}=100$ & $X_{11241}=100$ & $X_{11241}=100$ & $X_{11241}=100$ \\
\hline & $X_{21311}=300$ & $X_{11231}=100$ & $X_{21131}=50$ & $X_{21141}=50$ & $X_{12122}=20$ \\
\hline & $X_{31232}=200$ & $X_{11241}=100$ & $X_{21241}=100$ & $X_{21211}=100$ & $X_{21111}=90$ \\
\hline & $X_{32312}=300$ & $X_{21131}=70$ & $X_{21311}=300$ & $X_{21321}=300$ & $X_{21141}=50$ \\
\hline & & $X_{21151}=80$ & $X_{31231}=100$ & $X_{31211}=100$ & $X_{21321}=300$ \\
\hline & & $X_{21211}=100$ & $X_{31241}=100$ & $X_{31241}=100$ & $X_{22122}=10$ \\
\hline & & $X_{21221}=100$ & $X_{32312}=300$ & $X_{32322}=300$ & $X_{31211}=100$ \\
\hline & & $X_{21241}=100$ & & & $X_{31241}=100$ \\
\hline & & $X_{31211}=100$ & & & $X_{32322}=300$ \\
\hline & & $X_{31221}=100$ & & & \\
\hline & & $X_{31231}=100$ & & & \\
\hline & & $X_{31241}=100$ & & & \\
\hline & & $X_{31251}=100$ & & & \\
\hline & $I_{31}=20 I_{32}=20$ & $I_{11}=20$ & $I_{11}=20$ & $I_{11}=20$ & $I_{12}^{\prime}=60$ \\
\hline & $I_{11}^{\prime}=60$ & $I_{13}=20$ & $I_{12}=80$ & $I_{21}=10$ & $I_{13}^{\prime}=40$ \\
\hline & $I_{12}^{\prime}=40$ & $I_{14}=40$ & $I_{21}=210$ & $I_{12}^{\prime}=60$ & $I_{14}^{\prime}=20$ \\
\hline & $I_{13}^{\prime}=40$ & $I_{21}=10$ & $I_{22}=120$ & $I_{13}^{\prime}=40$ & $I_{22}^{\prime}=40$ \\
\hline & $I_{14}^{\prime}=20$ & $I_{22}=20$ & $I_{23}=30$ & $I_{14}^{\prime}=20$ & $I_{23}^{\prime}=10$ \\
\hline & $I_{21}^{\prime}=30$ & $I_{24}=10$ & $I_{33}=200$ & $I_{22}^{\prime}=40$ & $I_{24}^{\prime}=30$ \\
\hline & $I_{23}^{\prime}=60$ & & $I_{14}^{\prime}=20$ & $I_{23}^{\prime}=10$ & \\
\hline & $I_{24}^{\prime}=30$ & & $I_{24}^{\prime}=30$ & $I_{24}^{\prime}=30$ & \\
\hline Total $Z$ & 24,155 & 25,830 & 24,845 & 25,135 & 25,375 \\
\hline$Z_{1}$ & 17,000 & 18,850 & 17,000 & 17,050 & 17,39 \\
\hline$Z_{2}$ & 340 & 600 & 460 & 460 & 460 \\
\hline$Z_{3}$ & 2,650 & 2,650 & 2,650 & 2,650 & 2,650 \\
\hline$Z_{4}$ & 240 & 280 & 910 & 1150 & 1,000 \\
\hline$Z_{5}$ & 3,935 & 3,450 & 3,825 & 3,825 & 3,875 \\
\hline
\end{tabular}

GA to a wide variety of supplier selection problems have been very promising among the evolutionary algorithms for both single- and multi-objective problems $[10,13,14,20,23,26]$. Therefore, encouraged by its noticeable positive features, a GA is proposed in this study to handle large-scale problem instances.

\subsection{Chromosome representation}

In order to solve the problem, a chromosome is designed with four parts. The first part of the chromosome is a $P \times(T-1)$ matrix, which is used to calculate the quantity of the leftover products after consumption in each period. The elements of this matrix belong to the standard normal distribution function. Since the premise of the problem is to fulfil customer demand in each period, the available inventory level of the products in every period is determined in this part of the chromosome. The second part of the chromosome is an $I \times(T-1)$ matrix representing the amount of raw materials left after consumption in each period. The elements of this matrix also have a standard normal distribution. The amount of the raw materials needed in each period is calculated by the following equation:

The Demand for raw material $i$ in period $t$

$$
=\sum_{p} Y_{p t} \alpha_{i t} \quad \forall p, t>1 .
$$


With regard to the values of the second part of the chromosome, the purchasing amount of the raw materials can be calculated by the following equations in each period:

The purchasing amount of raw material $i$ in period $t$ $=$ The demand of raw material $i$ in period $t$ $\times[1+$ The elements of matrix $(i, t)]$ -The inventory amount of the previous period (for $t<T$ )

and:

The purchasing amount of raw material $i$ in period $T$ $=$ The demand of raw material $i$ in period $T$

-The inventory amount of the previous period

After determining the required purchasing amount of raw materials by the first two parts of the chromosome, the third part determines how to provide the purchase quantities belonging to each supplier by an $i \times j \times t$ matrix with elements taking values from $[0,1]$, each corresponding to a supplier and a raw material in a period. The elements of this matrix show the supply priority of the specific raw material by the specific supplier in each period. The chromosome numbers are used in compliance with the supplier capacity constraints in a way that the supplier with the highest priority is selected to provide the maximum amount of raw materials. The other suppliers will be selected in order of precedence to meet the total demand. In the fourth part of the chromosome, carriers are allocated to each selected supplier. This part is a $j \times l \times t$ matrix with $[0,1]$ element values and it is used to cover the capacity constraints of the carriers.

\subsection{Initialization of the population}

There are different approaches for producing the initial population, which is the starting point of the algorithm. In this study, we have adopted random generation of solutions approach to create the initial population. In this way, for each population, a chromosome with the specifications described in the previous subsection is randomly generated. The feasibility conditions that must be assessed after generating each chromosome are:

- Limitation of time availability for production;

- Product storage capacity constraints; and

- Storage capacity constraints for the raw materials.

\subsection{Fitness function}

Each chromosome is a plausible solution to the problem, which is used to calculate the fitness value of the objective function. Since the objective function is based on costs, smaller objective function values generate higher fitness values.

\subsection{Selection strategy}

The solutions of GA evolve from each generation to the next one. Evolution of the population is realized through GA operators such as crossover, mutation, and elitism. The hatching process in which we need to select the solutions (chromosomes) from the population is accomplished through a crossover operation. Different methods have been proposed to select the parents (Boltzmann selection, tournament, rank, steady state, etc.). The selection method by the Roulette wheel, which has been used in this study, is among the most popular ones. Moreover, the elitism idea has been implemented in the GA by which a percentage of the best chromosomes in the current population are kept for the next generation.

\subsection{Crossover operation}

The crossover operator is implemented based on a guide matrix with binary elements. For each chromosome, there is a guide matrix with equal dimensions. To generate new offspring, the crossover operator is applied to the parents selected through Roulette wheel approach. If the value of the corresponding element in the guide matrix equals 1 , the corresponding values of the parent element will be replaced. Otherwise, the element is left unchanged. Figure 3 represents an example of a crossover operation.

\subsection{Elitism operation}

According to this operator, the chromosomes having the best fitness values in the active generation are automatically carried over to the next generation. This operator causes further improvement in the efficiency of GA by preventing the loss of good solutions. In other words, the solution quality obtained by the GA will not decrease from one generation to the next one.

\subsection{Local search}

In each iteration of the provided GA, we search to find better neighbourhoods around better solutions in the population. A certain percentage of the best solutions for each generation of the algorithm will be examined in order to find better neighbourhoods. To create a neighbourhood for the algorithm in every part of the chromosome, new elements are calculated through the following equation:
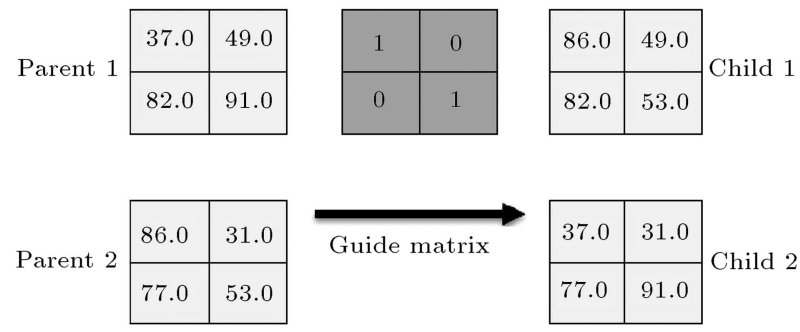

Figure 3. An example of crossover operation. 
New element $=(1+R) *$ Old element.

In this equation, " $R$ " is a random number with the standard normal distribution. If the new element takes a value more than 1 , it will be set to 1 and if it takes a value less than zero, it will be considered equal to zero. Searching to find a better neighbourhood stops after finding a better solution. Otherwise, after certain steps and finding no better solution, it stops.

\subsection{Mutation operation}

In the mutation operation, we randomly switch rows or columns of the chromosome. For the parts of the chromosome that have more than one dimension, this action is applied to each and every dimension. Figure 4 shows an example of a mutation operation.

\subsection{Termination criterion}

The most common termination criteria in GA include the fixed number of iterations (or a fixed length of computational time), an arbitrary number of iterations at which no further improvement is realized in the objective function, and when the predefined threshold for the objective function value is reached. As for the proposed design, we let the iterations proceed to a specified number; however, the algorithm terminates if no improvement is achieved during 50 consecutive iterations.

\subsection{Parameter setting of the proposed $G A$}

We have borrowed the same parameters setting method form Gorji et al. [26] and Dai and Zheng [34] by performing a considerable amount of experimental analyses. To find the optimal solution efficiently, some parameters of the GA require to be set appropriately, including the population size, maximum number of generations, crossover rate, mutation rate, elitism rate, and the local search rate. According to this statement, the following parameters will be set to achieve the best optimal minimum cost possible in a short time:

- Population size. It is noteworthy that if the population size is huge, it would probably lead to very slow rate of convergence and elude sub-optimal solutions. On the other hand, a small population may result in a premature convergence and quick rate of convergence. Thus, in the presented article, two choices are available for population size, namely 250 and 350, which result in moderately better

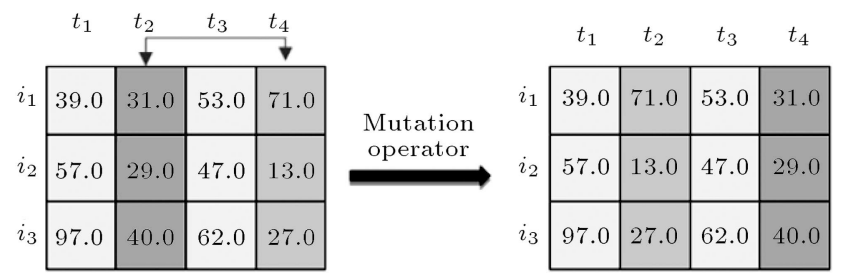

Figure 4. An example of mutation operation. solutions through extensive experiments being done on different values for this parameter.

- The maximum generation number. Two options have been applied here: 150 and 200 .

- Crossover and mutation rates. Crossover and mutation are the ways to generate new individuals, which are mostly used to provide exploitation and exploration, respectively. In this paper, each of them gives two choices: 0.85 and 0.93 for crossover, 0.1 and 0.18 for mutation.

- Elitism rate. Elitism guarantees that the solution quality obtained by the GA will not decrease from one generation to the next one. In this paper, two choices have been considered, which are 0.1 and 0.25 .

- Local search rate. Two options have been applied here: 0.1 and 0.2 .

As can be seen in Table 9, based on our computational experiments, the following combination obtains the best value for the objective function in the shortest time: population size, maximum generation, crossover rate, mutation rate, elitism rate, and the rate of local search are set to $350,150,0.93,0.1,0.25$, and 0.2 , respectively. Of course, these parameters cannot guarantee a globally optimal solution.

\section{Results for the numerical examples}

In this section, 10 small and 10 large sample problems are presented to examine the problem in different scales. The experiments were performed on a PC with an Intel dual core i5 $\mathrm{CPU}$ at $2.5 \mathrm{GHz}$ and 4 GB of RAM. The results obtained by the GA (coded in MATLAB software) are compared with those of the exact method using LINGO 12. Twenty samples with different dimensions, illustrated in Table 10, were considered and the values of the common parameters used in these samples are shown in Table 11.

The results obtained for small-scale and largescale problems are presented in Tables 12 and 13, respectively. The average run-time is derived from the average of five-time implementations of the algorithm. The gap is obtained through comparing the averages of the best solution values among those five-time implementations with those of the exact method. Figure 5 . demonstrates the values of the objective function over small-scale samples.

As the dimension of the problem increases (samples 11 to 20), the exact method fails to reach the optimal solution in a reasonable time while the proposed GA achieves near optimal solutions in a fairly short run with a little variation. It is noteworthy that, for samples 19 and 20, the exact method fails to find a feasible solution even in 2,000 seconds. Hence, we terminated it in 4,000 seconds of run time. 
Table 9. Best value and time for different parameters.

\begin{tabular}{|c|c|c|c|c|c|c|c|}
\hline $\begin{array}{c}\text { Population } \\
\text { size }\end{array}$ & $\begin{array}{l}\text { Maximum } \\
\text { generation }\end{array}$ & $\begin{array}{c}\text { Crossover } \\
\text { rate }\end{array}$ & $\begin{array}{c}\text { Mutation } \\
\text { rate }\end{array}$ & $\begin{array}{c}\text { Elitism } \\
\text { rate }\end{array}$ & $\begin{array}{c}\text { Local search } \\
\text { rate }\end{array}$ & $\begin{array}{l}\text { Best objective } \\
\text { function }\end{array}$ & $\begin{array}{l}\text { Time } \\
\text { (sec) }\end{array}$ \\
\hline 250 & 200 & 0.93 & 0.18 & 0.25 & 0.2 & 31167 & 130 \\
\hline 250 & 200 & 0.93 & 0.18 & 0.1 & 0.2 & 31079 & 135 \\
\hline 250 & 200 & 0.93 & 0.1 & 0.25 & 0.2 & 31027 & 118 \\
\hline 250 & 200 & 0.85 & 0.18 & 0.25 & 0.2 & 31007 & 104 \\
\hline 250 & 200 & 0.93 & 0.1 & 0.1 & 0.2 & 30996 & 81 \\
\hline 250 & 200 & 0.85 & 0.18 & 0.1 & 0.2 & 31200 & 116 \\
\hline 250 & 200 & 0.85 & 0.1 & 0.25 & 0.2 & 31072 & 75 \\
\hline 250 & 200 & 0.85 & 0.1 & 0.1 & 0.2 & 31066 & 85 \\
\hline 250 & 200 & 0.93 & 0.18 & 0.25 & 0.1 & 31270 & 66 \\
\hline 250 & 200 & 0.93 & 0.18 & 0.1 & 0.1 & 31210 & 144 \\
\hline 250 & 200 & 0.93 & 0.1 & 0.25 & 0.1 & 31020 & 112 \\
\hline 250 & 200 & 0.85 & 0.18 & 0.25 & 0.1 & 31200 & 72 \\
\hline 250 & 200 & 0.93 & 0.1 & 0.1 & 0.1 & 31039 & 92 \\
\hline 250 & 200 & 0.85 & 0.18 & 0.1 & 0.1 & 31131 & 95 \\
\hline 250 & 200 & 0.85 & 0.1 & 0.25 & 0.1 & 31138 & 99 \\
\hline 250 & 200 & 0.85 & 0.1 & 0.1 & 0.1 & 31162 & 122 \\
\hline 350 & 150 & 0.93 & 0.18 & 0.25 & 0.2 & 30957 & 119 \\
\hline 350 & 150 & 0.93 & 0.18 & 0.1 & 0.2 & 30962 & 152 \\
\hline 350 & 150 & 0.93 & 0.1 & 0.25 & 0.2 & 30930 & 103 \\
\hline 350 & 150 & 0.85 & 0.18 & 0.25 & 0.2 & 31098 & 113 \\
\hline 350 & 150 & 0.93 & 0.1 & 0.1 & 0.2 & 31040 & 202 \\
\hline 350 & 150 & 0.85 & 0.18 & 0.1 & 0.2 & 31070 & 130 \\
\hline 350 & 150 & 0.85 & 0.1 & 0.25 & 0.2 & 31132 & 104 \\
\hline 350 & 150 & 0.85 & 0.1 & 0.1 & 0.2 & 31158 & 149 \\
\hline 350 & 150 & 0.93 & 0.18 & 0.25 & 0.1 & 31017 & 108 \\
\hline 350 & 150 & 0.93 & 0.18 & 0.1 & 0.1 & 31054 & 118 \\
\hline 350 & 150 & 0.93 & 0.1 & 0.25 & 0.1 & 30969 & 107 \\
\hline 350 & 150 & 0.85 & 0.18 & 0.25 & 0.1 & 30988 & 73 \\
\hline 350 & 150 & 0.93 & 0.1 & 0.1 & 0.1 & 31008 & 134 \\
\hline 350 & 150 & 0.85 & 0.18 & 0.1 & 0.1 & 31146 & 93 \\
\hline 350 & 150 & 0.85 & 0.1 & 0.25 & 0.1 & 31186 & 99 \\
\hline 350 & 150 & 0.85 & 0.1 & 0.1 & 0.1 & 31037 & 105 \\
\hline
\end{tabular}

Table 10. Dimensions of samples.

\begin{tabular}{|c|c|c|c|c|c|c|c|c|}
\hline & Sample & $\begin{array}{c}\text { Raw } \\
\text { material } \\
(i)\end{array}$ & $\begin{array}{l}\text { Supplier } \\
\quad(j)\end{array}$ & $\begin{array}{c}\text { Break levels } \\
(k)\end{array}$ & $\begin{array}{l}\text { Product } \\
\qquad(p)\end{array}$ & $\begin{array}{c}\text { Period } \\
\quad(t)\end{array}$ & $\begin{array}{c}\text { Carrier } \\
(l)\end{array}$ & Considerations \\
\hline \multirow[t]{10}{*}{ Small-scale } & 1 & 1 & 2 & 3 & 1 & 2 & 2 & $j_{1}, j_{2}$ \\
\hline & 2 & 1 & 2 & 3 & 1 & 3 & 2 & $j_{1}, j_{2}$ \\
\hline & 3 & 2 & 2 & 3 & 2 & 3 & 2 & $j_{1}, j_{2}$ \\
\hline & 4 & 3 & 2 & 3 & 1 & 3 & 2 & $j_{2}, j_{3}$ \\
\hline & 5 & 3 & 3 & 3 & 1 & 3 & 2 & - \\
\hline & 6 & 3 & 3 & 3 & 2 & 3 & 2 & - \\
\hline & 7 & 2 & 2 & 3 & 2 & 5 & 2 & $j_{1}, j_{2}$ \\
\hline & 8 & 3 & 3 & 3 & 2 & 4 & 2 & - \\
\hline & 9 & 3 & 3 & 3 & 2 & 5 & 2 & - \\
\hline & 10 & 3 & 3 & 3 & 2 & 6 & 2 & - \\
\hline \multirow[t]{10}{*}{ Large-scale } & 11 & 3 & 3 & 3 & 2 & 10 & 2 & - \\
\hline & 12 & 3 & 5 & 3 & 2 & 9 & 2 & - \\
\hline & 13 & 4 & 3 & 3 & 3 & 10 & 2 & - \\
\hline & 14 & 3 & 5 & 3 & 3 & 10 & 3 & - \\
\hline & 15 & 4 & 10 & 3 & 3 & 13 & 3 & - \\
\hline & 16 & 3 & 12 & 3 & 3 & 15 & 3 & - \\
\hline & 17 & 3 & 10 & 3 & 3 & 15 & 3 & - \\
\hline & 18 & 3 & 15 & 3 & 3 & 10 & 3 & - \\
\hline & 19 & 3 & 15 & 3 & 3 & 15 & 3 & - \\
\hline & 20 & 3 & 15 & 3 & 3 & 20 & 3 & - \\
\hline
\end{tabular}


Table 11. Values of the parameters used in the samples.

\begin{tabular}{ll}
\hline Parameters & \multicolumn{1}{c}{ Values } \\
\hline$D_{p t}$ & $\sim$ uni $[20,50]$ \\
$O_{j t}$ & $\sim$ uni $[80,150]$ \\
$P_{i j k t}$ & $\sim$ uni $[10,30]$ \\
$h_{i t}$ & $\sim$ uni $[2,5]$ \\
$H_{p t}$ & $\sim$ uni $[4,9]$ \\
$P R_{p t}$ & $\sim$ uni $[10,20]$ \\
$C V_{j l t}$ & $\sim$ uni $[50,90]$ \\
$B_{i j k t}$ & $100,300,1000$ \\
$C R_{t}$ & $\sim$ uni $[800,1500]$ \\
$C P_{t}$ & $\sim$ uni $[100,200]$ \\
$C S_{i j t}$ & $\sim$ uni $[300,900]$ \\
$t_{p}$ & $\sim$ uni $[2,5]$ \\
$T_{t}$ & $\sim$ uni $[400,800]$ \\
$\alpha_{i p}$ & $\sim$ uni $[1,5]$ \\
$W i$ & $\sim$ uni $[1,7]$ \\
$U V_{l}$ & $\sim$ uni $[50,100]$ \\
$U N V_{l t}$ & $\sim$ uni $[30,60]$ \\
\hline
\end{tabular}

In Figure 6, it can be observed that the run times in the GA are more than those in the exact method for samples 1 to 8 , while in the rest of the samples, this trend has changed, showing the effectiveness of the presented GA. Figure 7 shows the rate of change in the objective function value in samples 11 to 20 . The gap in the solutions is very small, which is a persuasive proof for the effectiveness of the presented GA.

\section{Conclusion}

Today, due to the increasing demands and intense competition among product manufacturers, the need for multi-product productions along with an efficient

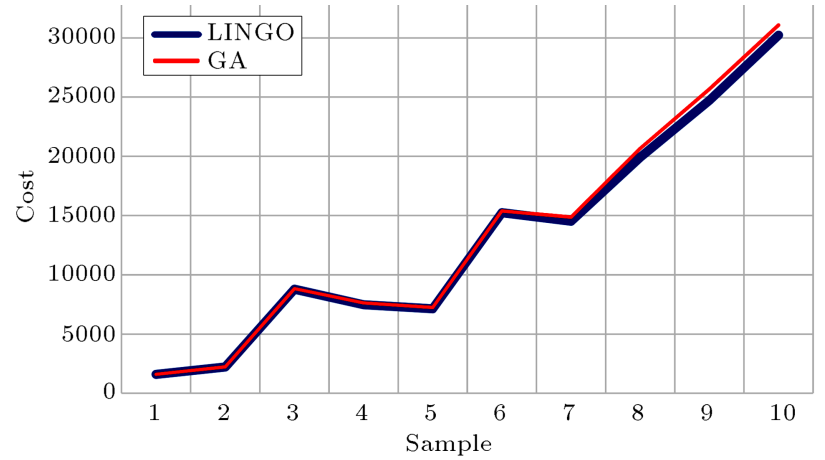

Figure 5. The objective function values for small-scale samples.

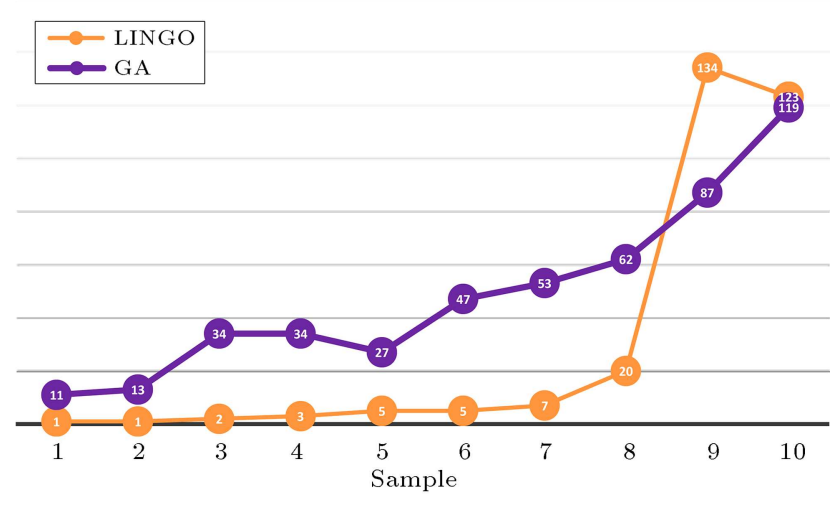

Figure 6. Run time comparison between GA and the exact method.

inventory management is felt more than ever. This paper presented a multi-product Mixed-Integer Linear Programming (MILP) model for supplier selection over a multi-period planning horizon. The objectives included the purchase cost of the raw materials from the suppliers, ordering costs, production costs, inventory holding costs of the raw materials and products, and the transportation costs. In the problem setting, the

Table 12. Computational results for the small-scale samples.

\begin{tabular}{|c|c|c|c|c|c|c|}
\hline \multirow[b]{2}{*}{ Sample } & \multicolumn{2}{|c|}{ LINGO } & \multicolumn{3}{|c|}{ Genetic Algorithm (GA) } & \multirow[b]{2}{*}{ Gap (\%) } \\
\hline & $\begin{array}{l}\text { Run time } \\
\quad(\mathrm{sec})\end{array}$ & $\begin{array}{l}\text { Optimal } \\
\text { solution }\end{array}$ & $\begin{array}{l}\text { Run time } \\
\text { (average of } \\
5 \text { runs) }\end{array}$ & $\begin{array}{l}\text { Solution value } \\
\text { (average of } \\
5 \text { runs) }\end{array}$ & $\begin{array}{c}\text { Best solution } \\
\text { value }\end{array}$ & \\
\hline 1 & 1 & 1,600 & 11 & 1,600 & 1,600 & 0.00 \\
\hline 2 & 1 & 2,220 & 13 & 2,230 & 2,230 & 0.45 \\
\hline 3 & 2 & 8,780 & 34 & $8,828.4$ & 8,806 & 0.29 \\
\hline 4 & 3 & 7,470 & 34 & 7,623 & 7,616 & 1.95 \\
\hline 5 & 5 & 7,125 & 27 & 7,239 & 7,235 & 1.54 \\
\hline 6 & 5 & 15,240 & 47 & 15,393 & 15,347 & 0.70 \\
\hline 7 & 7 & 14,515 & 53 & $14,862.4$ & 14,763 & 1.70 \\
\hline 8 & 20 & 19,925 & 62 & $20,663.3$ & 20,613 & 3.45 \\
\hline 9 & 134 & 24,731 & 87 & 25,684 & 25,561 & 3.35 \\
\hline 10 & 85 & 30,230 & 119 & 30,997 & 30,930 & 2.3 \\
\hline
\end{tabular}


Table 13. Computational results for the large-scale samples.

\begin{tabular}{|c|c|c|c|c|c|c|}
\hline \multirow[b]{2}{*}{ Sample } & \multicolumn{2}{|c|}{ LINGO } & \multicolumn{3}{|c|}{ Genetic Algorithm (GA) } & \multirow[b]{2}{*}{ Gap (\%) } \\
\hline & $\begin{array}{l}\text { Run time } \\
\quad(\mathrm{sec})\end{array}$ & $\begin{array}{c}\text { Best } \\
\text { solution }\end{array}$ & $\begin{array}{l}\text { Run time } \\
\text { (average of } \\
5 \text { runs) }\end{array}$ & $\begin{array}{c}\text { Solution value } \\
\text { (average of } \\
5 \text { runs) }\end{array}$ & $\begin{array}{c}\text { Best solution } \\
\text { value }\end{array}$ & \\
\hline 11 & 2,000 & 119,123 & 284 & 122,886 & 122440 & 2.78 \\
\hline 12 & 2,000 & $78,885.4$ & 224 & $82,118.4$ & 81384 & 3.16 \\
\hline 13 & 2,000 & 168,052 & 283 & 170,238 & 169740 & 1.00 \\
\hline 14 & 2,000 & 138,988 & 231 & 143,006 & 141980 & 2.15 \\
\hline 15 & 2,000 & 167,819 & 541 & 174,824 & 173940 & 3.64 \\
\hline 16 & 2,000 & 171,049 & 448 & 179,408 & 177200 & 3.59 \\
\hline 17 & 2,000 & 207,025 & 427 & 220,880 & 218030 & 5.31 \\
\hline 18 & 2,000 & 104,101 & 277 & 112,112 & 109710 & 5.38 \\
\hline 19 & 4,000 & 208,993 & 437 & 225,602 & 223220 & 6.80 \\
\hline 20 & 4,000 & 250,818 & 390 & 262,856 & 260390 & 3.81 \\
\hline
\end{tabular}

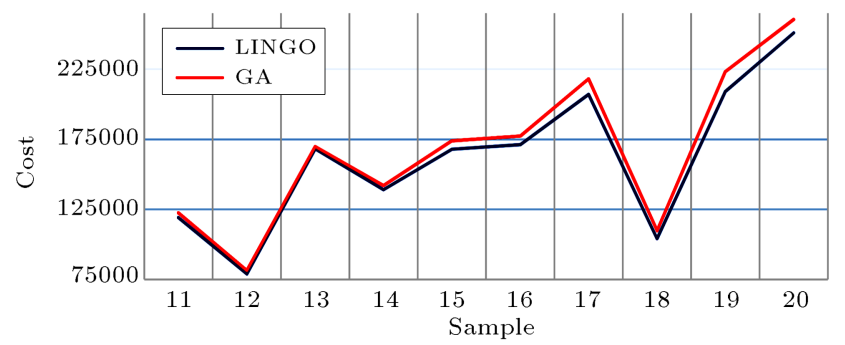

Figure 7. The objective function values for large-scale samples.

manufacturer was allowed to purchase the required raw material through the all-unit quantity discount plan offered by the suppliers, which were required to completely satisfy demands of customers. Different raw materials could be shipped by different carriers. The proposed model sought to determine which raw materials should be ordered, in what quantities, from which suppliers, by which transportation carriers, and in which periods. To solve the proposed model, an efficient GA was proposed and 20 small-scale and largescale samples were presented to show applicability of the approach. The results were compared with those of the exact method to show the performance of the proposed algorithm.

For the future research, the present model can be further developed by taking into account other assumptions such as the backlog or loss in demand fulfillment as well as introducing probabilistic and fuzzy parameters. In addition, other meta-heuristics can be employed to improve quality of the solutions and reduce the run time needed to solve the problem. Introducing multiple competing objectives to the problem setting can also serve as an interesting direction for the future research. There are some other related areas that can be inspiring to develop this work, e.g., sustainable supplier selection, green supplier selection, and implementing the MADM approach to cope with new problems regarding various optimization criteria $[35,36]$.

\section{References}

1. Aissaoui, N., Haouari, M., and Hassini, E. "Supplier selection and order lot sizing modeling: A review", Computers \& Operations Research, 34, pp. 3516-3540 (2007).

2. Mendoza, A. and Ventura, J.A. "Incorporating quantity discounts to the EOQ model with transportation costs", International Journal of Production Economics, 113, pp. 754-765 (2008).

3. Manerba, D. and Mansini, R. "An exact algorithm for the capacitated total quantity discount problem", European Journal of Operational Research, 222, pp. 287-300 (2012).

4. Mansini, R., Tocchella, B., and Savelsbergh, M. "The supplier selection problem with quantity discounts and truck load shipping", Omega, 40, pp. 445-455 (2012).

5. Zhang, J.L. and Chen, J. "Supplier selection and procurement decisions with uncertain demand, fixed selection costs and quantity discounts', Computers and Operations Research, 40, pp. 2703-2710 (2013).

6. Nazari-Shirkouhi, S., Shakouri, H., Javadi, B., et al. "Supplier selection and order allocation problem using a two-phase fuzzy multi-objective linear programming", Applied Mathematical Modelling, 37, pp. 9308-9323 (2013).

7. Jolai, F., Neyestani, M.S., and Golmakani, H. "Multiobjective model for multi-period, multi-products, supplier order allocation under linear discount", International Journal of Management Science and Engineering Management, 8, pp. 24-31 (2013). 
8. Meena, P.L. and Sarmah, S.P. "Multiple sourcing under supplier failure risk and quantity discount: A genetic algorithm approach", Transportation Research Part E, 50, pp. 84-97 (2013).

9. Babić, Z. and Perić, T. "Multiproduct vendor selection with volume discounts as the fuzzy multi-objective programming problem", International Journal of Production Research, 52, pp. 4315-4331 (2014).

10. Liao, Z. and Rittscher, J. "A multi-objective supplier selection model under stochastic demand conditions", International Journal of Production Economics, 105(1), pp. 150-159 (2007).

11. Choudhary, D. and Shankar, R. "Joint decision of procurement lot-size, supplier selection, and carrier selection", Journal of Purchasing and Supply Management, 19, pp. 16-26 (2013).

12. Choudhary, D. and Shankar, R. "A goal programming model for joint decision making of inventory lot- size, supplier selection and carrier selection", Computers and Industrial Engineering, 71, pp. 1-9 (2014).

13. Rezaei, J. and Davoodi, M. "Multi objective models for lot-sizing with supplier selection", International Journal of Production Economics, 130(1), pp. 77-86 (2011).

14. Lee, A.H.I., Kang, H.Y., Lai, Ch.M., et al. "An integrated model for lot sizing with supplier selection and quantity discounts", Applied Mathematical Modelling, 37, pp. 4733-4746 (2013).

15. De Boer, L., Labro, E., and Morlacchi, P. "A review of methods supporting supplier selection", European Journal of Purchasing and Supply Management, 7, pp. 75-89 (2001).

16. Ho, W., Xu, X., and Dey, P.K. "Multi-criteria decision making approaches for supplier evaluation and selection: A literature review", European Journal of Operational Research, 202, pp. 16-24 (2010).

17. Chai, J., Liu, J.N.K., and Ngai, E.W.T. "Application of decision-making techniques in supplier selection: A systematic review of literature", Expert Systems with Applications, 40, pp. 3872-3885 (2013).

18. Ghodsypour, S.H. and O'Brien, C. "The total cost of logistics in supplier selection, under conditions of multiple sourcing, multiple criteria and capacity constraint", International Journal of Production Economics, 73(1), pp. 15-27 (2001).

19. Basnet, C. and Leung, J.M.Y. "Inventory lot-sizing with supplier selection", Computers and Operations Research, 32, pp. 1-14 (2005).

20. Rezaei, J. and Davoodi, M. "A joint pricing, lot-sizing, and supplier selection model", International Journal of Production Research, 50(16), pp. 4524-4542 (2012).

21. Mendoza, A. and Ventura, J.A. "Analytical models for supplier selection and order quantity allocation", Applied Mathematical Modelling, 36, pp. 3826-3835 (2012).
22. Senyigit, E. "The optimization of lot sizing with supplier selection problem in multi-echelon defective supply chain network", Mathematical and Computer Modelling of Dynamical Systems, 18, pp. 273-286 (2012).

23. Aliabadi, D.E., Kaazemi, A., and Pourghannad, B. "A two-level GA to solve an integrated multi-item supplier selection model", Applied Mathematics and Computation, 219, pp. 7600-7615 (2013).

24. Ventura, J.A., Valdebenito, V.A., and Golany, B. "A dynamic inventory model with supplier selection in a serial supply chain structure", European Journal of Operational Research, 230, pp. 258-271 (2013).

25. Kang, H.Y. and Lee, A.H.I. "A stochastic lot-sizing model with multi-supplier and quantity discounts", International Journal of Production Research, 51, pp. 245-263 (2013).

26. Gorji, M.H., Setak, M., and Karimi, H. "Optimizing inventory decisions in a two-level supply chain with order quantity constraints", Applied Mathematical Modelling, 38, pp. 814-827 (2014).

27. Cardenas-Barron, L.E., Gonzalez-Velarde, J.L., and Trevino-Garza, G. "A new approach to solve the multiproduct multi-period inventory lot sizing with supplier selection problem", Computers and Operations Research, 64, pp. 225-232 (2015).

28. Zaheri, F., Zandieh, M., and Taghavifard, M.T. "Bilevel programming for supplier selection under quantity discount policy", Scientia Iranica, E, 24(4), pp. 2095-2104 (2017).

29. Ghaniabadi, M. and Mazinani, A. "Dynamic lot sizing with multiple suppliers, backlogging and quantity discounts", Computers and Industrial Engineering, 110, pp. 67-74 (2017).

30. Alfares, H.K. and Turnadi, R. "Lot sizing and supplier selection with multiple items, multiple periods, quantity discounts, and backordering", Computers and Industrial Engineering, 116, pp. 59-71 (2018).

31. Suriyan, S. and Rungreunganun, V. "Multi product dynamic lot-sizing with supplier selection under quantity discount and budget constraints", International Journal of Applied Engineering Research, 13(2), pp. 1373-1380 (2018).

32. Kanchanaruangrong, N. and Woarawichai, C. "Modeling and solving of multi-product inventory lot-sizing with supplier selection under quantity discounts", International Journal of Applied Engineering Research, 13(10), pp. 8708-8713 (2018).

33. Zaheri, F., Zandieh, M., Taghavifard, M.T., et al. "A bi-level programming model to solve supplier selection and lot-sizing problem addressing quantity discounts and transportation cost", Industrial Engineering and Management Systems, 17(2), pp. 267-280 (2018).

34. Dail, Z. and Zheng, X. "Design of close-loop supply chain network under uncertainty using hybrid genetic algorithm: a fuzzy and chance-constrained programming model", Computers and Industrial Engineering, 88, pp. 444-457 (2015). 
35. Hajikhani, A., Khalilzadeh, M. and Sadjadi, S.J. "A fuzzy multi-objective multi-product supplier selection and order-allocation problem in supply chain under coverage and price considerations: An urban agricultural case study", Scientia Iranica, E, 25(1), pp. 431439 (2018).

36. Rabieh, M., Rafsanjani, A.F., Babaei, L., et al. "Sustainable supplier selection and order allocation: an integrated Delphi method, fuzzy TOPSIS and multi-objective programming model", Scientia Iranica, E, 26(4), pp. 2524-2540 (2019). DOI: 10.24200/SCI.2018.5254.1176

\section{Biographies}

Salman Jameh Abrishami received his BS and MS degrees in Industrial Engineering from Sadjad University of Technology and University of Bojnord, Iran, in 2012 and 2015, respectively. Currently, he is a $\mathrm{PhD}$ candidate of Industrial Engineering at Imam Hossein Comprehensive University, Tehran, Iran, with special focus on mega systems analysis.

Hashem Vahdani is an Assistant Professor at University of Bojnord, Bojnord, Iran. He holds BS, $\mathrm{MS}$, and $\mathrm{PhD}$ in Industrial Engineering from Sharif University of Technology, University of Tehran, and Sharif University of Technology in Iran, respectively. His research interests cover applied operations research, production management, supply chain management with special focus on sustainable development and green chains, and warranty analysis.

Babak Rezaee is an Assistant Professor in Industrial Engineering Department at Ferdowsi University of Mashhad (FUM). His research interests lie in utilizing artificial intelligence and operations research to tackle decision-making problems. Some of the applications he has worked on are supply chain risk management, energy policy and modelling, modelling uncertainty in operations and services, and designing fuzzy rule-based systems. 